\title{
AVALIAÇÃO DA QUALIDADE FÍSICO-QUÍMICA E MICROBIOLÓGICA DA ÁGUA DE BARREIRO UTILIZADA NO FABRICO DE QUEIJO ARTESANAL EM JUCATI - PE
}

\section{EVALUATION OF PHYSICAL-CHEMICAL AND MICROBIOLOGICAL QUALITY OF WATER BARREIRO USED IN THE MANUFACTURE OF ARTISANAL CHEESE IN JUCATI - PE}

João Rufino de Freitas Filho ${ }^{1}$, João Sales de Souza Filho ${ }^{1}$, Phelipe Matheus de Moraes Cavalcanti ${ }^{1}$, Janieire Dorlamis Cordeiro Bezerra ${ }^{1}$, Juliano Carlo Rufino de Freitas ${ }^{2}$, Jucleiton José Rufino de Freitas $^{3}$, Jucarlos Rufino de Freitas ${ }^{3}$.

${ }^{1}$ Universidade Federal Rural de Pernambuco joaoveronice@yahoo.com.br

${ }^{2}$ Universidade Federal de Campina Grande- UFCG

${ }^{3}$ Universidade Federal de Pernambuco- UFPE.

\begin{abstract}
Resumo
A avaliação da qualidade da água de barreiro utilizada pela população de Jucati - Pernambuco é relevante tanto para o fabrico de queijo coalho, quanto para a saúde humana. Desse modo, este trabalho objetivou avaliar as características físico-químicas (condutividade elétrica temperatura, pH, alcalinidade, dureza, turbidez, cor e cloretos) e microbiológicas (coliformes fecais) de amostras de águas barreiro utilizada no fabrico de queijo coalho no município de Jucati Pernambuco. Os resultados das análises físico-químicas demonstraram que as amostras de água, estão dentro dos padrões estabelecidos pelas legislações vigentes. Os resultados das análises físico-químicas demonstraram que as amostras de água, estão dentro dos padrões estabelecidos pelas legislações vigentes. Porém, a amostra 3 foi considerada reprovada em relação ao nível de $\mathrm{pH}$, com valor 4,83. Os resultados microbiológicos identificaram que as amostras de água no período seco encontram-se dentro dos padrões microbiológicos estabelecidos pela legislação, apresentando ausência de coliformes.
\end{abstract}

Palavras-chave: Qualidade da água, parâmetros físico-químico, fabrico de queijo.

\section{Introdução}

Atualmente a sociedade mundial vive um momento de fortes reflexões quanto aos problemas ambientais provocados pelo grande crescimento da população do planeta e pelo modo de produção capitalista, sendo este último, apontado por muitos autores como o protagonista principal dessa problemática e de tantas outras. Com a superprodução capitalista e suas consequências ao meio 
ambiente, a educação ambiental tornou-se objeto de estudo de centros de pesquisa, institutos e universidades que elaboram seus documentos e resultados de suas pesquisas. Entretanto, a preocupação maior em implementar e mudar práticas tradicionais de relacionamento com o meio ambiente tem sido tarefa da sociedade civil representada em sua grande maioria por movimentos sociais e organizações populares (associações, sindicatos, comunidades).

A água tem fundamental importância para a manutenção da vida no planeta, e, portanto, falar da relevância dos conhecimentos sobre a água, em suas diversas dimensões, é falar da sobrevivência da espécie humana, da conservação e do equilíbrio da biodiversidade e das relações de dependência entre seres vivos e ambientes naturais.

A água é formada por uma molécula de oxigênio e duas de hidrogênio. Sabe-se que é o constituinte de grande parte do planeta, porém apenas uma pequena parcela esta disponível para uso já que é utilizada água doce e esta compreende 2,5\% no ambiente. Apesar de sua importância este recurso natural está seriamente ameaçado devido à poluição. De acordo com MOTA et al. (2006) ao longo dos últimos 50 anos, o crescimento acelerado das populações e o desenvolvimento industrial e tecnológico vêm comprometendo as fontes disponíveis de água doce do planeta.

Devido às consequências negativas que a poluição dos recursos naturais causa à natureza, faz necessária uma mudança de atitude em relação ao ambiente natural. Conforme descrito por RENNER et al. (2010) a preservação dos recursos hídricos é fundamental para a sobrevivência de qualquer espécie vegetal ou animal.

A água é um dos elementos indispensáveis à vida, sendo uma das principais substâncias ingeridas pelo ser humano (OKURA; SIQUEIRA, 2005; NETO et al., 2006). A água doce corresponde a $1 \%$ de toda a água do planeta e, em seu estado natural, representa um dos componentes mais puros, porém esta característica vem se alterando e hoje ela é um importante veículo de transmissão de inúmeras doenças (REIS; HOFFMANN, 2006).

Para preservar as águas e solos do planeta é necessário que a humanidade se conscientize da necessidade de ter atitudes que ajudem a preservar a natureza, esta pode surgir através da sensibilização provocada pela educação ambiental. Segundo a lei 9795/99 educação ambiental (EA) é um processo por meio do qual o indivíduo e a coletividade constroem valores sociais, conhecimentos, habilidades, atitudes e competências voltadas para a conservação do meio ambiente.

Segundo LA CORTE BACCI e PATACA (2008), a presença ou ausência de água escreve a história, cria culturas e hábitos, determina a ocupação de territórios, vence batalhas, extingue e dá vida às espécies, determina o futuro de gerações. Nosso planeta não teria se transformado em ambiente apropriado para a vida sem a água. Desde a sua origem, os elementos hidrogênio e oxigênio se combinaram para dar origem ao elemento-chave da existência da vida. 
A disponibilidade de água semi-árido nordestino é reduzida e caracterizada por marcantes diferenças entre o período chuvoso e o seco. Embora haja regiões com precipitação de $800 \mathrm{~mm}$, outras não excedem os $200 \mathrm{~mm}$. A sazonalidade e a falta de sustentabilidade de algumas políticas públicas dificultam o desenvolvimento do ser humano do campo e cria relação de dependência daquele que não tem água com "o dono da água", gerando insegurança, impotência de ação e falta de autoestima nos mais pobres.

Indicadores de desenvolvimento sustentável (BRASIL, 2004), mostram que na área rural nordestina, apenas $22,7 \%$ da população tem acesso ao fornecimento de água por sistemas de abastecimento coletivo e 58\% coleta água para beber e para o uso diário de poços, nascentes e açudes. Essas fontes representam grave risco à saúde pública e contribuem com a manutenção dos ciclos endêmicos de doenças infecciosas de veiculação hídrica, com altas taxas de mobilidade e mortalidade, especialmente em crianças com menos de cinco anos de idade (AMBIENTE BRASIL, 2006).

Estudos realizados por DINIZ et al $(1995,2005)$ e CEBALLOS et al $(1998,2003)$ na zona rural do estado da Paraíba, mostraram elevada contaminação fecal das águas de pequenos barreiros, olhos d'água e açudes usados para beber sem tratamento prévio e para usos domésticos em geral.

Em áreas de produção agrícola, destacam-se como fatores que reduzem a qualidade das águas superficiais e subterrâneas, o cultivo e manejo do solo e o uso sucessivo de agrotóxicos, fertilizantes, despejos residuais urbanos e industriais e adubos orgânicos, que causam acúmulo de metais potencialmente tóxicos (MPT) e contaminação microbiológica por coliformes totais e fecais, nos ecossistemas aquáticos e terrestres (CHEN et al., 2006; FONSECA et al., 2011; HANI; PAZIRA, 2011).

Segundo a Organização Mundial da Saúde cerca de $80 \%$ das doenças que ocorrem em países em desenvolvimento são veiculadas pela água contaminada por microrganismos patogênicos (COELHO et al., 2007). Isto se deve ao fato de apenas $30 \%$ da população mundial ter água tratada e os outros $70 \%$ terem poços como fonte de água, facilitando assim sua contaminação (FERNANDEZ; SANTOS, 2007).

Com relação a contaminação microbiológica da água de barreiro está associada à utilização de fertilizantes orgânicos, geralmente estercos de animais e a falta de saneamento básico. De acordo com CRAUN et al.(2010) e FONSECA et al. (2011), o aumento considerável do número de patógenos nos corpos hídricos na área de produção agrícola ocorre principalmente pelo escoamento de esgotos domésticos e sistemas sépticos, como fossas, ricas em excretas humanas ou pela ação das chuvas. 
Os coliformes são os micro-organismos mais utilizados para indicar contaminação fecal de humanos ou animais em água, o que a torna imprópria para o consumo humano (MICHELINA et al., 2006). De acordo com a Portaria número 518 do ano de 2004 do Ministério da Saúde (BRASIL, 2004), define-se como água para consumo humano aquela livre de Escherichia coli ou coliformes termotolerantes, sendo recomendado sua ausência em 100 mL (FORTUNA et al., 2007). Segundo os registros do Ministério da Saúde, no ano de 2004 foram registrados cerca de 2,4 milhões de casos de diarreia no Brasil, e considera-se quea água seja responsável por $60 \%$ das internações por diarreia no país. O custo gerado para o tratamento de doenças transmitidas ou causadas por águas contaminadas, segundo o Ministério da Saúde, é equivalente a US\$ 2,7 bilhões por ano (ADEODATO, 2006).

Por outro lado, a preocupação com a qualidade da água é incipiente, pois os trabalhos científicos só visavam o aspecto quantitativo, todavia com o crescimento populacional, acompanhado com o desenvolvimento industrial e a superutilização dos recursos hídricos, o fator qualidade passou a ser importante. Desse modo é fundamental que os recursos hídricos apresentem condições físico-químicas adequadas para a utilização dos seres vivos, devendo conter substâncias essenciais à vida e estar isentos de outras substâncias que possam produzir efeitos prejudiciais aos organismos. Cada sistema lótico possui características próprias, o que torna difícil estabelecer uma única variável como um indicador padrão para qualquer sistema hídrico. Neste sentido, a busca em trabalhos de campo é a obtenção de índices de qualidade de água que reflitam resumidamente e objetivamente as alterações, com ênfase para as intervenções humanas, como o uso agrícola, urbano e industrial (COUILLARD e LEFEBVRE, 1985).

Portanto, a análise de qualidade da água é de extrema importância para sua utilização uma vez que concentrações anômalas de determinado elemento podem causar prejuízos à saúde pública e ao meio ambiente. Logo o presente trabalho teve como objetivo avaliar a qualidade físico-química da água de barreiro usada no fabrico de queijo artesanal no município de Jucati - PE, em dois períodos distintos (chuvoso e seco).

\section{Material e Métodos}

\section{Coleta de amostras}

Foram coletadas amostras de água às 9:00h da manhâ, no mesmo ponto em períodos distintos, 2 (duas) no período chuvoso (nos meses de maio e junho), e 4 (quatro) no período seco (nos meses de agosto, setembro, outubro) em barreiro localizado no município de Jucati -PE. As amostras $(1000 \mathrm{~mL})$ foram armazenado em caixa de isopor com gelo e enviadas ao Laboratório de Ensino de Química Orgânica da Universidade Federal Rural de Pernambuco/Unidade Acadêmica de 
Garanhuns da Universidade Federal Rural de Pernambuco, onde permaneceram mantidas sob refrigeração até o momento das análises.

\section{Conhecendo um Barreiro}

De acordo com SOUZA (1999) com prognóstico de períodos de seca e se conhecendo a variação temporal e espacial das precipitações, é de suma importância o fornecimento de subsídios ao planejamento da época de plantio e melhor adequação ao uso da irrigação. Neste contexto, alternativas inovadoras, como o barreiro para consumo humano e animais, são de grande valor para a região semiárida nordestina. A maior parte dos barreiros encontrados em JUCATI- PE é de forma circular ou ovulada, com profundidade de 1,6 a 2,8 m, acumulando água por um período médio de 8 a 12 meses, em anos de chuvas regulares. A forma dos barreiros, na maioria dos casos, impede um acúmulo maior de água, corroborando com as afirmações de REBOUÇAS e MARINHO (1972) de que a maior parte das chuvas que ocorrem na região Nordeste, é mal aproveitada.

\section{Método de análises}

\section{Análises físico-químicas}

Os parâmetros físico-químicos avaliados foram os seguintes:

a) A condutividade elétrica foi realizada pelo método condutivimétrico, que se baseia na medição da resistência da amostra e dado em condutância específica (condutividade elétrica a 20 ou $\left.25^{\circ} \mathrm{C}\right)$.

b) o $\mathrm{pH}$ foi obtido utilizando pHmetro (Marconi);

c) a temperatura foi medida em campos com um termômetro que consistiu em um tubo fino de vidro graduado preenchido com mercúrio.

d) para a determinação de cloretos utilizou-se $100 \mathrm{~mL}$ de amostra, e adicionou-se uma pequena porção de carbonato de cálcio $\left(\mathrm{CaCO}_{3}\right)$ e 3-4 gotas de cromato de potássio $\left(\mathrm{K}_{2} \mathrm{CrO}_{4} 5 \%\right)$. Depois, titulou-se com nitrato de prata $\left(\mathrm{AgNO}_{3} \quad 0,01 \mathrm{~mol} / \mathrm{L}\right)$ até viragem de amarelo para vermelho-tijolo (SILVA et al., 2005).

Os seguintes parâmetros carbonatos, bicarbonatos, hidróxidose dureza foram efetudados de acordo com as técnicas adotadas no Manual da Fundação Nacional de Saúde - FUNASA (2004).

Todas as análises foram realizadas em triplicata.

\section{Análises microbiológicas}

Quanto a identificação de coliformes fecais, foi utilizada a técnica dos tubos múltiplos, método qualitativo, que permite determinar o número mais provável (NMP) dos microrganismos. Foram utilizados 10 tubos contendo $10 \mathrm{~mL}$ de Caldo Lauril Sulfato Triptose suplementado com 
50mg/L de 4-metil-umbeliferil- $\beta$-D-glucuronídeo (LST-MUG), em concentração dupla, contendo tubos de Durhan invertidos. Em cada tubo foram inoculados $10 \mathrm{~mL}$ da amostra, e todos os tubos foram incubados em estufa bacteriológica a $35^{\circ} \mathrm{C} \pm 0,5^{\circ} \mathrm{C}$ por $48 \pm 2$ horas (SILVA et al., 2005b).

\section{Resultados e Discussão}

\section{Análises físico-químicas}

Segundo LEAL et al., (2009) a determinação da qualidade da água para suas diversas finalidades envolve certo grau de complexidade. Faz-se necessário considerar que, além dos fatores naturais, como a interação da água com as rochas, outros fatores, como a interferência da ação do homem, com a introdução de novas substâncias que promovem a alteração da qualidade da água. Dessa forma, a localização de fontes de poluição nas proximidades de poços, nascentes e rios é um fato observado em diversos ambientes.

$\mathrm{Na}$ tabela abaixo, estão relacionados os valores dos parâmetros físicos e químicos, analisados para água de barreiro usada no fabrico de queijo coalho artesanal, nos períodos chuvoso e seco.

Tabela 1. Parâmetros físico-químicos da agua de barreiro usada no fabrico de queijo Coalho produzidos em Jucati - PE.

\begin{tabular}{|c|c|c|c|c|c|c|c|c|c|c|c|}
\hline & Cond $^{*}$ & pH & $\mathbf{T}^{*}$ & Cloreto & Dureza & $\mathbf{C a}$ & Mg & $\mathbf{O H}$ & $\mathrm{CO}_{3}{ }^{-2}$ & $\mathbf{B}^{* * * *}$ & $\mathrm{CO}_{2}$ \\
\hline 1 & 366,67 & 7,13 & 26,233 & 54,576 & 14,9567 & 3,893 & 2,58 & 0 & 0 & 5 & 3,13 \\
\hline 2 & 416,20 & 6.33 & 27,533 & 142 & 84,667 & 18 & 9,6 & 0 & 0 & 3,633 & 17,1 \\
\hline 3 & 408,40 & 4.83 & 25,200 & 15,96 & 110,667 & 28 & 9,6 & 0 & 0 & 11,5 & 24 \\
\hline 4 & 393,40 & 7,27 & 25,200 & 17,183 & 125 & 30 & 12 & 0 & 0 & 10 & 20 \\
\hline $5^{* * * * *}$ & 264,57 & 7,48 & 24,533 & 8,87 & 171 & 40 & 18 & 0 & 0 & 5 & 16 \\
\hline $6^{* * * *}$ & 464,30 & 7,76 & 24,467 & 16,9867 & 91,33 & 34 & 1,2 & 0 & 0 & 11,5 & 16,01 \\
\hline Média & 383,51 & 6,618 & 25,527 & 42,59595 & 99,59845 & 25,648 & 8,830 & 0 & 0 & 7,772 & 16,04 \\
\hline Desvio & 70,033 & 1,031 & 1,1702 & 51,32885 & 51,61777 & 12,899 & 6,206 & 0 & 0 & 3,612 & 7,026 \\
\hline${ }^{* * * * * * *} \mathrm{CV}$ & 18,260 & 15,57 & 4,5844 & 120,5017 & 51,82588 & 50,292 & 70,28 & 0 & 0 & 46,48 & 43,80 \\
\hline
\end{tabular}

Conforme a tabela 1, as medidas da condutividade registraram valores entre 366,67 a 416,20 $\mathrm{mg} / \mathrm{mL}$ para o período seco, e entre 264,57 e $464,30 \mathrm{mg} / \mathrm{mL}$ para o período chuvoso. A condutividade elétrica está relacionada com a presença de íons dissolvidos na água, que são partículas carregadas eletricamente. Quanto maior for a quantidade de íons dissolvidos, maior será a condutividade elétrica da água que pode variar também de acordo com a temperatura e o $\mathrm{pH}$ 
(MOTA, 1995). A condutividade elétrica também fornece uma boa indicação das modificações na composição de uma água, especialmente na sua concentração mineral, mas não fornece nenhuma indicação das quantidades relativas dos vários componentes. À medida que mais sólidos dissolvidos são adicionados, a condutividade da água aumenta. Altos valores podem indicar características corrosivas da água (CETESB, 2005).

A legislação em vigor não determina valores para a variável CE, porém, a CETESB, orienta no sentido de que quando os valores forem superiores a $50 \mu \mathrm{S} \mathrm{cm}-1$, deve-se verificar outros fatores (esgoto doméstico, fertilidade do solo da região, utilização de insumos agrícolas,etc.) que podem influenciar os resultados. Logo os resultados dos valores obtidos, de acordo com a tabela 1 nas estão acima dos valores propostos pela CETESB.

As temperaturas da água medidas no local variaram de 24,20 a $24,30^{\circ} \mathrm{C}$ no período chuvoso, e 25,30 a $27,3^{\circ} \mathrm{C}$ no período seco. Essa elevação deve-se ao aumento de radiação no corpo d'água, observada no período seco. De acordo com a CETESB (2005), a temperatura desempenha um papel principal de controle no meio aquático, condicionando as influências de uma série de parâmetros físicoquímicos. A temperatura superficial é influenciada por fatores tais como latitude, altitude, estação do ano, período do dia, taxa de fluxo e profundidade. A elevação da temperatura em um corpo d'água geralmente é provocada por despejos industriais (indústrias canavieiras, por exemplo) e usinas termoelétricas (CETESB, 2005). A temperatura da água exerce influência direta sobre vários tipos de organismos aquáticos e sobre o teor de gases dissolvidos na água, principalmente o oxigênio e o gás carbônico (BRANCO, 1986).

Tomando-se por base, os valores de $\mathrm{pH}$ encontrados para o período chuvoso $(6,48$ a 7,76) e seco $(4,83$ a 7,21), a amostra 3 apresenta abaixo do padrão e a demais nos padrões estabelecidos pela Resolução do CONAMA n 357/05, a qual estabelece limites de 6,0 a 9,0. A influência do pH sobre os ecossistemas aquáticos naturais dá-se diretamente devido a seus efeitos sobre a fisiologia das diversas espécies (CETESB,1993). Por outro lado, de acordo com CONTE e LEOPOLDO (2001) o pH das águas pode ser alterado pelo despejo de efluentes domésticos e industriais ou pela lixiviação de rochas e da erosão de áreas agrícolas, onde são utilizados corretivos e fertilizantes

As médias obtidas de dureza para as amostras variaram de $14,00 \mathrm{mg} / \mathrm{L}$ a $125 \mathrm{mg} / \mathrm{L}$, para o período seco e $91,33 \mathrm{mg} / \mathrm{L}$ a $171 \mathrm{mg} / \mathrm{L}$ para o período chuvoso, sendo assim classificadas como águas moles ou brandas. De acordo com BRASIL (2004), todas as amostras estavam dentro dos padrões de potabilidade por ela estabelecidos, que é de até $500 \mathrm{mg} / \mathrm{L}$.

$\mathrm{O}$ valor da alcalinidade medidas em $\mathrm{mg} / \mathrm{L}$ de $\mathrm{CaCO}_{3}$ - no período chuvoso está compreendido entre 34,0 a 40,0 e no período seco de 3,93 a 30,0. Os teores de concentração apresentados podem ser resultantes da decomposição da matéria orgânica, visto que os íons bicarbonatos são provenientes desse processo. A alcalinidade representa a capacidade que um 
sistema aquoso tem de neutralizar (tamponar) ácidos a ele adicionados. Esta capacidade depende de alguns compostos, principalmente bicarbonatos $\left(\mathrm{HCO}_{3}\right)$, carbonatos $\left(\mathrm{CO}_{3}\right)$ e hidróxidos $(\mathrm{OH})$.

$\mathrm{O}$ teor de cloretos é um indicador de poluição por esgotos domésticos nas águas naturais. $\mathrm{O}$ valor de cloreto medido no período chuvoso variou de 8,86 a $16,86 \mathrm{mg} / \mathrm{L}$ e no período seco 15,98 a 142,0 mg/L. Sendo assim, a água nos dois períodos encontra-se dentro dos padrões estabelecidos pela Resolução CONAMA n 357/05, a qual estabelece o limite de Cloreto total de $250 \mathrm{mg} / \mathrm{L}$.

\section{Análises microbiológicas}

As bactérias do grupo coliforme são consideradas os principais indicadores de contaminação fecal e assume importância como parâmetro indicador da possibilidade da existência de microorganismos patogênicos (CETESB, 2005). Por outyro lado, As bactérias coliformes termotolerantes reproduzem-se ativamente a $44,5^{\circ} \mathrm{C}$ e são capazes de fermentar o açúcar. O uso das bactérias coliformes termotolerantes para indicar poluição sanitária mostra-se mais significativo que o uso da bactéria coliforme "total", porque as bactérias fecais estão restritas ao trato intestinal de animais de sangue quente.

A determinação do quantitativo de bactérias do grupo coliformes foi realizada e observou-se que nas amostras do período chuvoso os resultados ficaram acima de MNP > 1,1/100ml, não atendendo a portaria de No $1469 / 2000$ do Ministério da Saúde, devido ao escoamento de despejos de dejetos de animais. Também analisamos a água do período seco e o resultado obtido foi de MNP $<1,1 / 100 \mathrm{~mL}$, atendendo, portanto a portaria do Ministério da Saúde. Os resultados são expressos na tabela 2.

Tabela 2 - Resultado das amostras de água de barreiro usada no fabrico de queijo coalho artesanal em relação a coliformes.

\begin{tabular}{lcccccc}
\hline Análise & Amostra & Amostra & Amostra & Amostra & Amostra & Amostra \\
& 1 & 2 & 3 & 4 & $5^{*}$ & $6^{*}$ \\
\hline Coliformes a $35^{\circ} \mathrm{C}$ & $<1,1 \times 10^{3}$ & $<1,1 \times 10^{3}$ & $<1,1 \times 10^{3}$ & $<1,1 \times 10^{3}$ & $1,5 \times 10^{3}$ & $1,4 \times 10^{3}$ \\
\hline${ }^{*}$ Chuveso
\end{tabular}

${ }^{*}$ Chuvoso

A evidência de coliformes nas análises microbiológicas pode ter vários motivos: a) à utilização de fertilizantes orgânicos, geralmente estercos de animais e a falta de saneamento básico no entorno do barreiro; b) escoamento de dejetos de animais e de pessoas pela ação das chuvas; c) acesso de animais e de pessoas, para fazer higiene pessoal, contribuindo para a baixa condição sanitária das suas águas.

\section{Conclusões}

As águas dos barreiros são utilizadas no abastecimento doméstico, no fabrico de queijo coalho, na irrigação de hortaliças e plantas frutíferas e na criação de espécies destinadas à 
alimentação humana. Segundo a resolução do Conselho Nacional do Meio Ambiente (CONAMA) no 20, 18/06/86, estas águas seriam classificadas como Classe Especial, já que o abastecimento doméstico é feito sem desinfeção prévia; mas para esta classe, segundo o Art. $3^{\circ}$ da mesma resolução, o uso destas águas fica vinculado à ausência de coliformes totais em qualquer amostra realizada.

Analisando-se os resultados obtidos e nas condições em que o experimento foi desenvolvido, pode-se concluir que a águas de barreiro utlizada no fabrico de queijo coalho artesanal, de forma geral, encontram-se em condições que poderiam ser definidas como não alarmantes, por não apresentarem valores muito diferentes daqueles estabelecidos pela Legislação, como pode ser visto a seguir:

- Coliformes totais foram encontrados em todas as amostras, porém a Legislação do CONAMA de 2005 não coloca limites para coliformes totais, sendo permitida a presença dos mesmos;

- Para coliformes fecais, apenas as amostras 5 e 6 apresentaram valores acima do permitido, indicando que estas águas estão impróprias do ponto de vista sanitário, uma vez que os queijos estão sujeitas à contaminação por microorganismos e podem por em risco a saúde da população que as consomem;

- Com realção a variável codutividade elétrica, todos os valores obtidos foram a $50 \mu \mathrm{S} \mathrm{cm}^{-1}$, conforme orientação do CETESB (2005);

- No caso do pH, os resultados se enquadram nos valores estabelecidos pelo CONAMA;

- Os cátions $\mathrm{Ca}^{+2}$ e o $\mathrm{Mg}^{+2}$ ocorrem naturalmente na água, sendo que a sua origem pode estar associada à dissolução de rochas carbonatadas pela água subterrânea, minerais ricos em magnésio, ou a influência de água salina (com elevados teores destes cátions). Das 6 amostras analisadas, todas apresentaram valores entre 50 e $150 \mathrm{mg} / \mathrm{l}$ de $\mathrm{CaCO}_{3}$, caracterizando-se essas águas com dureza moderada, ou meio duras. O maior valor identificado foi de 40,00 mg/l de $\mathrm{CaCO}_{3}$ e o menor valor de 3,893 .

\title{
5. Agradecimentos
}

Os autores do trabalho agradecem a FACEPE pelo suporte financeiro.

\begin{abstract}
The evaluation of the quality of the water of barreiro used by population of Jucati - Pernambuco is of great importance for the manufacture of cheese and human health. Thus, this study aimed to evaluate the physicochemical (electrical conductivity, temperature, $p H$, alkalinity, total hardness, turbidity, chlorides and color) and microbiological characteristics (fecal coliforms) of barreiro water used in the manufacture of artisanal cheese in the city of Jucati-Pernambuco. The results of physic chemical analyzes showed that the water samples are within the standards established by the
\end{abstract}


legislation. However, sample 3 was considered to be deprecated in relation to the pH level, with values of 4.83. The microbiological results identified that all watermarks during the dry period are within the microbiological standards established by law, with the absence of coliforms.

Key-words: Water quality, physical-chemical parameters, manufacture of cheese

\section{Referências}

ADEODATO, S. O consumo consciente da água. Bio nutrição e saúde, v. 1, n. 2, 2006.

AMBIENTE BRASIL. Desertificação. Disponível em: http://www.ambientebrasil. com.br Acesso em: 21 de Jul. 2006.

BRANCO, S. M. Hidrologia aplicada à engenharia sanitária. 3. ed. São Paulo: CETESB, 1986. 640 p.

BRASIL. Ministério da Saúde. Portaria $\mathrm{n}^{\circ} 518$ de 25 de março de 2004. Dispõe sobre os procedimentos e responsabilidades relativos ao controle e vigilância da qualidade da água para consumo humano e seu padrão de potabilidade. Diário Oficial (da) República Federativa do Brasil, Brasília, DF, 2004.

Portaria $n^{\circ} .518$ de 25 de março de 2004. Dispõe sobre os procedimentos e responsabilidades relativos ao controle e vigilância da qualidade da água para consumo humano e seu padrão de potabilidade. Brasília: Ministério da Saúde, 2005. (Série Legislação de Saúde).

CEBAlloS, B. S. O.; KÖNIG, A.; OLIVEIRA, J. Dam reservoir eutrophication: a simplified technique for a fast diagnosis of environmental degradation. Water Research, v. 32, n. 11, p. 3477-3483, 1998. http://dx.doi.org/10.1016/S0043-1354(98)00095-5

CEBAllos, B. S. O; SOARES, N. E.. E.; MORAES, M. R; CATÃO, R. .M .R.; KONIG, A. Microbiologic al aspects of an urban river used for 135 unrestricted irrigation in thesemi-arid region of north-east Brazil. Water Science and Technology, v. 47, n. 3., p. 51-57. IWA - International Water Association, London, UK, 2003.

CETESB. Controle da Qualidade da Água para Consumo Humano: Bases Conceituais e Operacionais. São Paulo, 1993. CETESB. Qualidade da água. São Paulo. Disponível em: 〈http://www.CETESB.sp.gov.br/Agua/rios/curiosidades.asp〉. Acesso em: 20 out. 2005.

CONTE, M. L., LEOPOLDO, P. R. Avaliação de recursos hídricos: Rio Pardo, um exemplo. São Paulo: Editora UNESP, 2001. $141 \mathrm{p}$.

CHEN, G. C.; HE, Z. L.; STOFELlA, P. J.; YANG, S. Y.; YANG, J. Y.; CALVERT, D. V.; Leaching potential of heavy metals $(\mathrm{Cd}, \mathrm{Ni}, \mathrm{Pb}, \mathrm{Cu}$ and $\mathrm{Zn}$ ) from acidic sandy soil amended with dolomite phosphate rock (DPR) fertilizers. Journal of Trace Elements in Medicine and Biology. v. 20, p. 127-133, 2006. http://dx.doi.org/10.1016/j.jtemb.2006.01.008

COELHO, D. A.; SILVA, P. M. F.; VEIGA, S. M. O. M.; FIORINI, J. E. Avaliação da qualidade microbiológica de águas minerais comercializadas em supermercados da cidade de Alfenas, MG. Revista Higiene Alimentar, São Paulo, v. 21, n. 151, p. 88-92, maio 2007.

CONAMA - Conselho Nacional do Meio Ambiente. Resolução CONAMA n 357, de 17 de março de 2005. Brasília, 2005 .

CONAMA - Conselho Nacional do Meio Ambiente, Resolução n²0 de 18/06/1986. Dispõe sobre a classificação das águas doces, salinas e salobras do território nacional, 1986.

COUILLARD, D.; LEFEBVRE, Y. Analysis of water quality indices. Journal of Environmental Management, v.21, p.161-179, 1985.

CRAUN, G. F.; BRUNKARD, J. M.; YODER, J. S.; ROBERTS, V. A.; CARPENTER, J.; WADE, T.; CADERON, R. L.; ROBERTS, J. M.; BEACH, M. J.; ROY, S. L. Causes of Outbreaks Associated with Drinking Water in the United States from 1971 to 2006. Clinical Microbiology Reviews, v. 23, n. 3,p. 507-528, 2010. http://dx.doi.org/10.1128/CMR.00077-09 
DINIZ, C.R.; KONIG. A.; CEBALLOS, B.S.O.; Corpos lênticos temporários do Agreste paraibano. Aspetos sanitários e físico-químicos. In VIII Congresso Brasileiro de Microbiologia. Santos. 1995. Anais. Santos/SP, 1995. p. 24.

DINIZ, C. R.; CEBALLOS, B. S. O.; BARBORA, J. E. L. Uso de macrófitas aquáticas como solução ecologica para melhorar a qualidade da água. Revista de Engenharia Agrícola e Ambiental. Campina Grande/PB, v. 9, n. 4, p.216230, 2005 [suplem]

FERNANDEZ, A.T.; SANTOS, V. C. Avaliação de parâmetros físico-químicos e microbiológicos da água de abastecimento escolar, no município de Silva Jardim, RJ. Revista Higiene Alimentar, São Paulo, v. 21, n. 154, p. 9398, set. 2007.

FONSECA, J. M.; FALLON, S. D.; SANCHEZ, C. A.; NOLTE, K. D. Escherichia coli survival in lettuce field following its introduction through different irrigation systems. Journal of Applied Microbiology, v. 110, p. 893-902, 2011. http://dx.doi.org/10.1111/j.1365-2672.2011.04942.x

FORTUNA, J. L.; RODRIGUES, M. T.; SOUZA, S. L.; SOUZA, L. Análise microbiológica da água dos bebedouros do campus da Universidade Federal de Juiz de Fora (UFJF): coliformes totais e termotolerantes. Revista Higiene Alimentar, São Paulo, v. 21, n. 154, p. 103-105, jul./ago. 2007.

FUNASA. Fundação Nacional de Saúde. Portaria no 1.469/2000, de 29 de dezembro de 2000. Aprova o controle e vigilância da qualidade da água para consumo humano e seu padrão de potabilidade. Brasília: Fundação Nacional de Saúde, 2001. 32 p.

FUNASA - Fundação Nacional da Saúde. Manual Prático de Análise de Água. 1 ed. Brasília: Fundação Nacional de Saúde, 2004

HANI, A.; PAZIRA, E. Heavy metals assessment and identification of their sources in agricultural soils of Southern Tehran, Iran. Environment Monitorament Assessment, v. 176, p. 677-691, 2011.

LA CORTE, D.; PATACA, E. M. Educação para a água. Estudos avançados, v. 22, n. 63, p. 211-226, 2008.

LEAL, C. M.; ANDRADE JÚNIOR, A. S.; SOUSA, V. F.; SILVA, E. F. F.; BASTOS, E. A. Qualidade da água subterrânea para fins de irrigação na microrregião de Teresina, Piauí. Irriga, Botucatu, v.14, n.3, p.276-288, 2009.

MiChElinA, A. de F.; BRONHAROA, T. M.; DARÉB, F.; PONSANOC, E. H. G. Qualidade microbiológica de águas de sistemas de abastecimento público da região de Araçatuba, SP. Revista Higiene Alimentar, São Paulo, v. 20, n. 147 , p. 90-95, dez. 2006.

MOTA, S. Preservação e conservação de recursos hídricos. 2. ed. Rio de Janeiro: ABES, 1995. 187p.

MOTA, M. B.R; MANZANARES, M.D; SILVA, R. A. L; Viabilidade de reutilização de água para vasos sanitários. Revista Ciências do Ambiente On-Line, v. 2; n. 2; Agosto, 2006.

NETO, A. F.; SILVA, J. L.; MOURA, G. J. B.; CALAZANS, G. M. T. Avaliação da qualidade da água potável de escolas públicas do Recife, PE. Revista Higiene Alimentar, São Paulo, v. 20, n. 139, p. 80-82, mar. 2006.

OKURA, M. H.; SIQUEIRA, K. B. Enumeração de coliformes totais e coliformes termotolerantes em água de abastecimento e de minas. Revista Higiene Alimentar, São Paulo, v. 19, n. 135, p. 86-91, set. 2005.

REIS, J. A.; HOFFMANN, P.; HOFFMANN, F. L. Ocorrência de bactérias aeróbias mesófilas, coliformes totais, fecais, e Escherichia coli, em amostras de águas minerais envasadas, comercializadas no município de São José do Rio Preto, SP. Revista Higiene Alimentar, São Paulo, v. 20, n. 145, p. 109-116, out. 2006.

RENNER, R.M. BITTENCUOURT, S.M. OLIVEIRA E.B. RADOMSKI, M.I.. Comportamento de espécies florestais plantadas. Embrapa Florestas. Colombo: PR, 2010. 38 p.

REBOUÇAS, A.C.; MARINHO, M.E. Hidrologia das secas do Nordeste do Brasil. Recife, PE, SUDENE - DRN, Divisão de Hidrologia, 1972. 126p. Brasil. SUDENE.

SILVA, N.; NETO, R. C.; JUNQUEIRA, V. C. A.; SILVEIRA, N. F. A. Contagem de heterotróficos. In: Manual de Métodos de Análise Microbiológica de Água. 1. ed. São Paulo: Livraria Varela, 2005. p. 27-40.

SILVA, N.; NETO, R. C.; JUNQUEIRA, V. C. A.; SILVEIRA, N. F. A. Contagem de heterotróficos. In: Manual de Métodos de Análise Microbiológica de Água. 1. ed. São Paulo: Livraria Varela, 2005b. p. 42-69. 
SOUZA, S. A. V. Programa computacional para simulação da ocorrência de veranicos e queda de produção. Piracicaba: ESALQ/USP, 1999. 124p. Tese Doutorado

TEIXEIRA, J. C. Vigilância da qualidade da água para consumo humano - utopia ou realidade? Estudo de caso: Juiz de Fora - MG. Associação Brasileira de Engenharia Sanitária e Ambiental, Rio de Janeiro, p. 1-4, 2005.

Submetido em 16 dez. 2013, Aceito para publicação em 11 jan. 2015, Publicado em 10 dez. 2015. 